\title{
SUPPLEMENT
}

\author{
Duygu Aydin \\ Emine G. G. Peker \\ Meryem D. Karakurt \\ Ayşe Gurel \\ Mustafa Ayyildiz 5 \\ Şule C. Cevber \\ Erdal Agar 5 \\ Senol Dane ${ }^{1}$
}

1Turgut Özal University, Faculty of Medicine, Department of Physiology, Ankara, Turkey,

${ }^{2}$ Agency of Pharmaceutical and Medical Device, Ministry of Health, ${ }^{3}$ Gaziantep, 4Turgut Özal University, Faculty of Medicine, Department of Pharmacology, Ankara, Turkey, ${ }^{5}$ Ondokuz Mayıs University, Faculty of Medicine, Department of Physiology

\section{Effects of Ginkgo biloba extract on brain oxidative condition after cisplatin exposure}

\section{Abstract}

Purpose: The purpose of this study was to evaluate the efficacy of Ginkgo biloba extract (EGb 761) on oxidative events of brain in cisplatin-administrated rats.

Methods: Rats were divided into four experimental groups: 1$)$ control $(\mathrm{n}=6) ; 2)$ cisplatin $(8 \mathrm{mg} / \mathrm{kg}$, intraperitoneally one dose, $\mathrm{n}=6) ; 3) \mathrm{EGb} 761(100 \mathrm{mg} / \mathrm{kg}$ intraperitoneally for 15 days, $n=6)$; and 4) cisplatin + EGb $761(n=6)$. After drug administration, rats were sacrificed and brain tissues were removed. Nitric oxide (NO), malondialdehyde (MDA) and glutathione (GSH) levels were evaluated in brain tissues.

Results: Single dose cisplatin administration significantly increased NO and GSH levels, but decreased MDA levels in brain tissue samples. EGb 761 treatment reversed the effects of cisplatin on NO and GSH levels, but did not affect the decreased MDA levels.

Conclusion: Results of the study indicate that oxidative stress can be an important pathogenetic mechanism of cisplatin-induced neurotoxicity. EGb 761, an standardized extract of $G$. biloba leaves that has antioxidant properties, may improve the oxidative stress-related neurological side effects of cisplatin.

Correspondence to:

Duygu Aydin

Turgut Özal University,

Faculty of Medicine, Department of Physiology, Ankara, Turkey

E-mail: daydin@turgutozal.edu.tr 
Cisplatin (CDDP) was the first platinum derivate that was used as an anticancer "antineoplastic" or "cytotoxic") drug and its beneficial effects have been shown in various cancerous diseases including bladder carcinoma, small cell bronchial carcinoma, and tumours in testes, ovary, endometric and prostatic cells [1]. Its clinical use is limited by its severe side effects, which include nephrotoxicity, ototoxicity, bone marrow toxicity, gastrointestinal toxicity and peripheral neurotoxicity [2,3]. Peripheral neurotoxicity is the most significant dose-limiting problem associated with CDDP use [4]. CDDP induces peripheral neurotoxicity that mainly affects the large myelinated nerve fibres of the dorsal root ganglia $[5,6,7]$. Neuropathologic examinations in animal models of CDDP have revealed pathologic changes in the dorsal-root ganglia [8]. Similarly, pharmacological examinations of neural tissue of patients treated with cisplatin have shown platinum accumulation in the dorsal-root ganglia that are not protected by the blood-brain-barrier [9].

Reactive oxygen species (ROS), including superoxide radical, hydrogen peroxide, hydroxyl radical and singlet oxygen, are generated during normal cellular metabolism $[10,11]$. Physiological levels of ROS can be scavenged by enzymatic (e.g., superoxide dismutase (SOD), catalase (CAT), glutathione peroxidase (GPx) and glutathione reductase (GR)) and non-enzymatic (e.g., vitamin $\mathrm{C}$, vitamin $\mathrm{E}$ and glutatione) antioxidant defence systems. Excessive ROS levels indicate decreased antioxidant defence ability or increased oxidative stress. Excess ROS reacts with nitric oxide (NO) to generate reactive nitrogen species (RNS) such as peroxynitrite [12]. ROS affect cell functions by directly acting on cell components, including lipids, proteins and DNA, and damaging their structure [13]. ROS are particularly active in the brain and neuronal tissue, and are involved in numerous cellular functions, including cell death and survival. A high metabolic rate and an abundant supply of the transition metals make the brain an ideal target for a free radical attack. In addition, the brain has a high susceptibility to oxidative stress due to the high lipid content and relatively lower regenerative capacity in comparison with other tissues. Oxidative stress is involved in the pathogenesis of a number of neurologic conditions and neurodegenerative disorders, including Alzheimer's disease, Parkinson's disease, amyotrophic lateral sclerosis and epilepsy [14-16]. An imbalanced overproduction of ROS can induce neuronal damage, leading to neuronal death by necrosis or apoptosis. Recent evidence indicates that cisplatin-induced side effects are, at least in part, due to the result of formation of ROS $[17,18]$.
Antioxidants are considered to be promising approaches to neuroprotection. Previous studies were demonstrated effects of antioxidants on neurodegenerative disorders in vitro and in animal models [19-23]. A number of studies have focused on the role of antioxidants in cisplatin toxicity. In animals, administration of antioxidants, such as vitamin E, vitamin C and selenium, seems to protect against cisplatin-induced renal and ototoxicity [24]. Also, the data obtained from human studies point that cisplatin treatment induces a significant decrease in plasma antioxidant levels because of oxidative stress [17].

The leaves of Ginkgo biloba tree have been used in traditional Chinese medicine for several hundred years. EGb 761 , a standardized extract of $G$. biloba leaves, is reported to alleviate symptoms in (or has been shown to have neuroprotective effects in) various central nervous system (CNS) disorders, such as dementia, cerebral insufficiency, ischemia, traumatic brain injuries, retinal degeneration, vestibular dysfunction and anxiety. It has also been reported to enhance mental and cognitive functions in experimental animals and human subjects [25]. One of the suggested mechanisms for its efficacious pharmacologic effects is its potent antioxidant action [26]. Studies have shown the protective effects of EGb 761 against oxidative stress, and these are closely related to its ability to scavenge free radicals, such as superoxide anion, hydroxyl, peroxyl radicals and nitric oxide [27-30]. EGb 761 has also been shown to prevent lipid peroxidation and enhances antioxidant enzyme activities [31]. The aim of the present study was to examine the effects of EGb 761 administration on the oxidative condition of rat brain tissue following cisplatin exposure.

\section{Materials and Methods}

\section{Animals and experimental groups}

Healthy adult female Wistar rats $(n=24)$ were used for the study. All rats had free access to commercial food and water and were maintained in an environment with controlled temperature and 12-hour light/dark cycles. All experiments were conducted with governmental approval according to local guidelines for the care and use of laboratory animals and the guidelines of the European Community Council for experimental animal care.

The rats were divided into four experimental groups: 1) control $(\mathrm{n}=6) ; 2)$ cisplatin $(8 \mathrm{mg} / \mathrm{kg}$, intraperitoneally one dose, $\mathrm{n}=6)$; 3) EGb 761 (100 mg/kg intraperitoneally for 15 days, $\mathrm{n}=6$ ); and 4) cisplatin + EGb 761 (cisplatin $8 \mathrm{mg} / \mathrm{kg}$, intraperitoneally one dose; EGb $761100 \mathrm{mg} / \mathrm{kg}$ 
intraperitoneally for 15 days) $(n=6)$. Under the urethane anaesthesia (1.2 g/kg, intraperitoneally) rats were sacrificed and brain tissues were removed, immediately frozen in liquid nitrogen and kept at $-30^{\circ} \mathrm{C}$ until assayed.

\section{Determination of MDA Levels}

Malondialdehyde (MDA) levels of brain tissue were determined according to the spectrophotometric method of Casini et al. (1986). Tissue samples were homogenized in nine volumes of cold $10 \%$ TCA solution and the homogenates were centrifuged for $15 \mathrm{~min}$ at $3000 \mathrm{~g}$ at $4^{\circ} \mathrm{C}$. The supernatants were transferred to glass test tubes containing $0.375 \%(\mathrm{w} / \mathrm{v})$ thiobarbituric acid and $0.02 \%(\mathrm{w} / \mathrm{v})$ butylated hydroxytoluene to prevent further lipid peroxidation during the subsequent steps. The samples were then heated for $15 \mathrm{~min}$ at $100^{\circ} \mathrm{C}$ in a boiling water bath, cooled and centrifuged to remove the precipitant. The absorbance of each sample was determined at $532 \mathrm{~nm}$.

\section{Determination of Glutathione Levels}

Glutathione (GSH) levels were determined by the modified Elman method (Aykaç et al. 1985). Tissue samples were homogenized in ice-cold trichloroacetic acid ( $1 \mathrm{~g}$ tissue plus 10 $\mathrm{ml} 10 \%$ trichloroacetic acid) in tissue homogenizer. After centrifugation at $3000 \mathrm{~g}$ for 10 minutes, $0.5 \mathrm{ml}$ of supernatant was added to $2 \mathrm{ml}$ of $0.3 \mathrm{M} \mathrm{Na}_{2} \mathrm{HPO}_{4} .2 \mathrm{H}_{2} \mathrm{O}$ solution. Then $0.2 \mathrm{ml}$ of dithionitrobenzoic acid solution $(0.4 \mathrm{mg} / \mathrm{ml} 1 \%$ sodium citrate) was added and the absorbance at $412 \mathrm{~nm}$ was measured immediately after mixing. The GSH levels were calculated using an extinction coefficient of $13.600 \mathrm{~mol} / \mathrm{cm}$.

\section{Determination of NO Levels}

$\mathrm{NO}$ values are given by the sum of nitrite and nitrate, which are the stable end products of nitric oxide. NO levels in tissue samples were determined by the Griess reaction (Green $e t$ al. 1982). The tissue samples were homogenized in five volumes of phosphate buffer ( $\mathrm{pH} 7.5$ ) and centrifuged at $2000 \mathrm{~g}$ for $5 \mathrm{~min}$ and $(0.5 \mathrm{ml}) 0.25 \mathrm{ml}$ of $0.3 \mathrm{M} \mathrm{NaOH}$ were added to the supernatants. After incubation for $5 \mathrm{~min}$ at room temperature, $0.25 \mathrm{ml}$ of $10 \%(\mathrm{w} / \mathrm{v}) \mathrm{ZnSO}_{4}$ was added for deproteinization. This mixture was then centrifuged at $14000 \mathrm{~g}$ for $5 \mathrm{~min}$, and then the supernatants were used for the Griess assay. The nitrate levels in tissue homogenates were determined spectrophotometrically, based on the reduction of nitrate to nitrite by $\mathrm{VaCI}_{3}$ (Miranda et al. 2001). The nitrite levels were measured by the Griess reaction. Sodium nitrite and nitrate solutions $(1,10,50,100 \mu \mathrm{M})$ were used as standards.

\section{Statistical analyses}

Statistical procedures were performed using SPSS statistical software package (version 12.0; SPSS Inc., Chicago, IL, USA). All analyses were carried out by one-way analysis of variance (ANOVA), followed by Bonferroni post hoc test to correct for multiple comparisons of treatments. Data are expressed as the mean \pm the standard error of the mean (SEM). The significance level was $p<0.05$.

\section{Results}

The control level of $\mathrm{NO}$ in brain was found as $149.5 \pm 7.9$ $\mu \mathrm{mol} / \mathrm{g}$ tissue. Figure 1 shows that NO level were increased significantly in cisplatin group $(\mathrm{p}<0.001)$ (Table 1$)$; however, NO levels of EGb 761 and Cisplatin+EGb 761 groups decreased significantly compared with control $(p<0.001)$ and cisplatin $(\mathrm{p}<0.001)$ groups. In the control group, the brain level of GSH was $3.1 \pm 0.3 \mu \mathrm{mol} / \mathrm{g}$ tissue. Figure 2 shows that GSH levels increased in all groups, compared with controls. The changes of GSH levels in cisplatin, cisplatin+EGb $761(p<$ $0.01)$ and EGb $761 \quad(p<0.05)$ groups were statistically significant. Assessment of brain MDA levels showed that the control level was $103 \pm 7.1 \mathrm{nmol} / \mathrm{g}$ tissue. Figure 3 shows that, brain MDA levels decreased in both cisplatin and cisplatin+EGb 761 groups compared with the control group $(p<0.001)$. There were no significant changes in EGB 761 group compared with the control $(\mathrm{p}>0.05)$ group.

\section{Discussion}

The present study evaluated the efficacy of EGb 761 on oxidative events in brains of cisplatin-administrated rats. Cisplatin is classified as an alkylating agent. Because alkylating

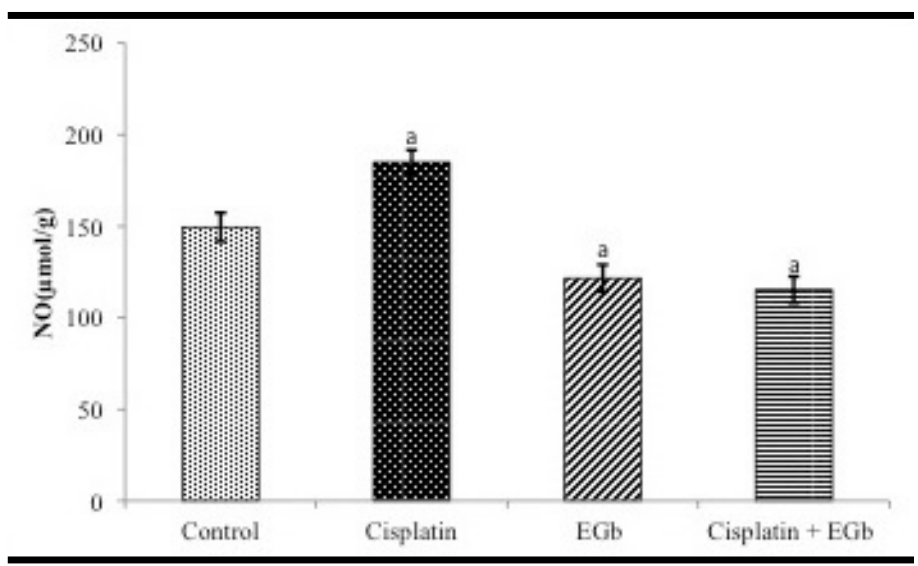

FIGURE 1. NO levels of brain according to groups. ${ }^{\mathrm{a}} p<0.001,{ }^{\mathrm{b}} p$ $<0.01$; $^{\mathrm{c}} p<0.05$, as compared with control group by Bonferroni post hoc test 


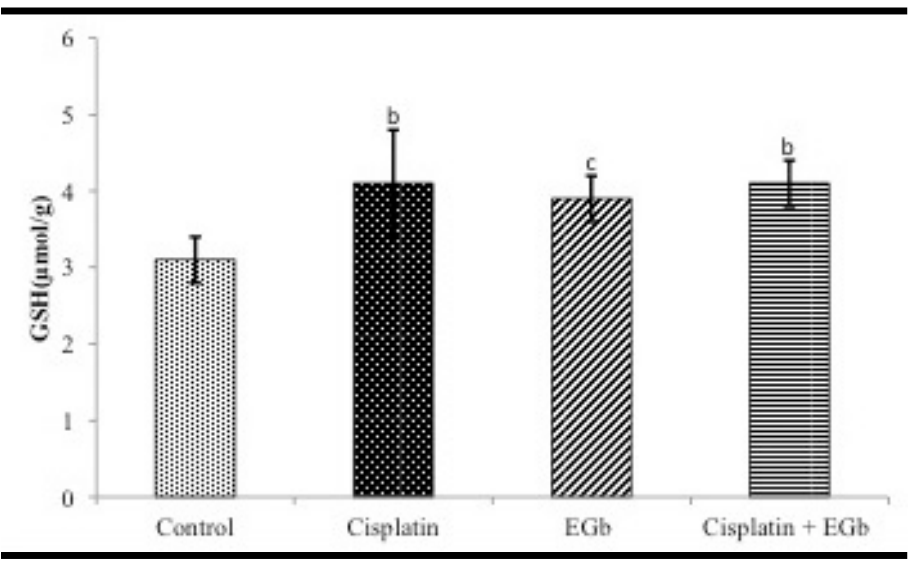

FIGURE 2. GSH levels of brain according to groups. ${ }^{\mathrm{a}} p<0.001,{ }^{\mathrm{b}} p$ $<0.01$; $^{\mathrm{c}} p<0.05$, as compared with control group by Bonferroni post hoc test

agents are most active in the resting phase of the cell, neuronal tissue is a target of their side effects. Cisplatin is reported to cross the blood-brain barrier only in limited amounts, as the brain-blood barrier limits protein-bound cisplatin penetration. In one study, cisplatin administration resulted in a peak CSF concentration as high as $40 \%$ of nonprotein bound cisplatin [32]. Despite the overall poor penetration of cisplatin across the brain-blood barrier, a number of CNS complications (including encephalopathy an epilepsy) may occur [33].

Our findings showed that cisplatin treatment increase NO levels of brain. The probable mechanism is that cisplatin elevated iNOS activity and induced the generation of large amounts of NO. Some investigators have shown that cisplatin increases inducible $\mathrm{NO}$ synthase (iNOS), which results in an increase in NO release [34-36]. Also, EGb 761 decreased NO levels when applied to the rats subjected to cisplatin. Kobuchi et al. [37] have reported that EGb 761 inhibits the enzymatic activity of iNOS. Consistent with previous studies, data from our study show a marked elevation in NO levels in brain tissue of cisplatin-administrated rats and this elevation in NO levels was significantly decreased by EGb 761 .

The increase of ROS, which attack the cell membrane lipids, occurs due to increased tissue lipid peroxidation as manifested by increased MDA levels. Administration of cisplatin causes an increase in lipid peroxidation and a decrease in enzymatic and non-enzymatic antioxidants that prevent or protect against lipid peroxidation in tissues. GSH is one of the non-enzymatic antioxidants that maintaining cell integrity because of its reducing specifications and accession in the cell metabolism. Several researchers have demonstrated increased lipid peroxidation and decreased antioxidant levels induced by cisplatin treatment in various tissues $[38,39,40,36]$. In

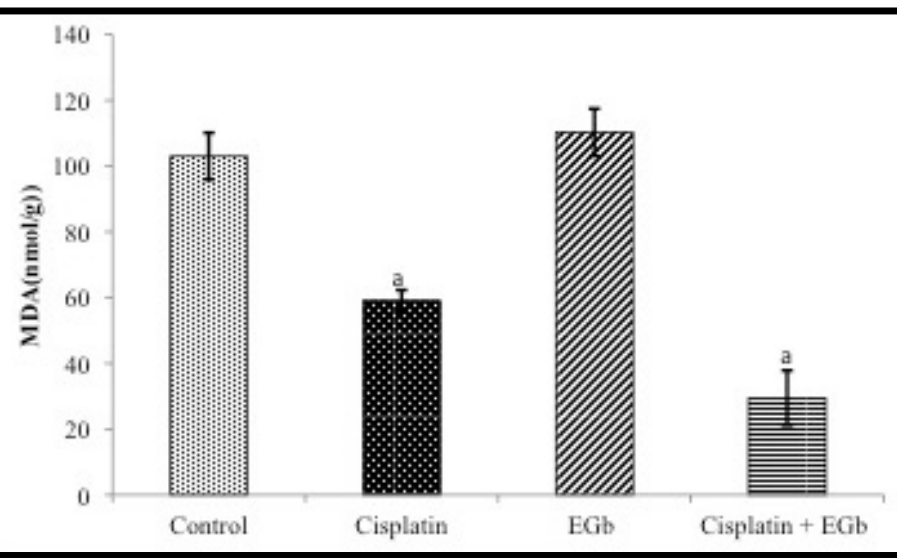

FIGURE 3. MDA levels of brain according to groups. ${ }^{\mathrm{a}} p<0.001$, ${ }^{\mathrm{b}}$ $p<0.01 ;{ }^{\mathrm{c}} p<0.05$, as compared with control group by Bonferroni post hoc test

contrast to these findings, we found higher GSH levels and lower MDA levels in the cisplatin group then in the control animals. A possible explanation for the reduction of MDA concentration may be enhanced formation of antioxidants in the brain tissue, which, due to the activity of ROS, would allow a consequent decrease in the production of MDA. The underlying mechanism of cisplatin-induced elevation in GSH level remains unclear. On the other hand, Yilmaz and coworkers [35] showed that cisplatin increased NO levels, with no change in MDA levels, in liver tissue in rats.

Some investigators have reported that EGb 761 protects several types of neurons in central nervous system, including cerebral cortex [41], cerebellum [42] and hippocampus [43] in conditions such as oxidative stress and ischemia. In the CNS, different mechanisms of action have been suggested for EGb 761, including antioxidant, anti-ischemic, anti-apoptotic and neurotransmitter modulatory effects [25]. Antioxidant effects of EGb 761 are related to its ability to acts as a free radical scavenger by preventing lipid peroxidation, enhancing GSH levels and GSH reductase activity [44]. The current study indicates that the administration of EGb 761 elevated GSH levels and decreased MDA levels significantly in cisplatin+EGb 761 group compared with controls. Similar to our finding, $\mathrm{Xu}$ et al. [45] showed that EGb 761 attenuated cisplatin-induced changes in serum superoxide dismutase (SOD) activity and MDA levels in guinea pigs. Also Güleç and colleagues [38] reported that EGb 761 administration increased GSH-Px activity and decreased NO levels in serum samples of cisplatin administrated rats.

In conclusion, this study suggests that Gingko biloba extract-EGb 761 protects against cisplatin-induced oxidative damage in the brain; however, further studies are required to 
reveal the mechanisms of these protective effects using different doses of EGb 761 and different experimental models.

\section{References}

1. Grolleau F, Gamelin L, Boisdron-Celle M, Lapied B, Pelhate M, Gamelin EA (2001) Possible explanation for a neurotoxic effect of the anticancer agent oxaliplatin on neuronal voltage-gated sodium channels. J Neurophysiol 85:2293-2297.

2. Hartmann JT, Lipp HP (2003) Toxicity of platinum compounds. Expert Opin Pharmacother 4:889-901

3. Boulikas T, Vougiouka M (2004) Recent clinical trial using cisplatin, carboplatin and their combination chemotherapy drugs. Oncol 11:559-595.

4. Thompson SWE, Davis LE, Kornfeld M, Hilgers RD, Standefer JC (1984) Cisplatin neuropathy: clinical, elctrophysiologic, morphologic, and toxicologic studies. Cancer 54:1269-1275.

5. Walsh TJ, Clark AW, Parhad IM, Green WR (1982) Neurotoxic effects of cisplatin therapy. Arch Neurol 39:719-720.

6. Cavaletti G, Tredici G, Marmiroli P, Petruccioli MG, Barajon I, Fabbrica D (1992) Morphometric study of the sensory neuron and peripheral nerve changes induced by chronic cisplatin (DDP) administration in rats. Acta Neuropathol (Berl) 84:364-371.

7. Tredici G, Braga M, Nicolini G, Miloso M, Marmiroli P, Schenone A, Nobbio L, Frattola L, Cavaletti G (1999) Effect of recombinant human nerve growth factor on cisplatin neurotoxicity in rats. Exp Neurol 159:551-558.

8. Gill JS, Windebank AJ (1998) Cisplatin-induced apoptosis in rat dorsal root ganglion neurons is associated with attempted entry into the cell cycle. Journal of Clinical Investigation 101:2842-2850.

9. Park SB, Krishnan AV, Lin CS, Goldstein D, Friedlander M, Kiernan MC (2008) Mechanisms underlying chemotherapy-induced neurotoxicity and the potential for neuroprotective strategies. Curr Med Chem 15:3081-3094.

10. Kontos HA (1989) Oxygen radicals in CNS damage. Chem Biol Interact 72:229-255.

11. Beit-Yannai E, Kohen R, Horowitz M, Trembovler V, Shohami E (1997) Changes of biological reducing activity in rat brain following closed head injury: a cyclic voltammetry study in normal and heat-acclimated rats. J Cereb Blood Flow \& Metab 17:273-279.

12. Brown GC, Borutaite V (2001) Nitric oxide, mitochondria, and cell death. IUBMB Life 52:189-195.
13. Kawai Y, Nakao T, Kunimura N, Kohda Y, Gemba M (2006) Relationship of intracellular calcium and oxygen radicals to Cisplatin-related renal cell injury. J Pharmacol Sci 100:65-72.

14. Perry G, Nunomura A, Hirai K, Zhu X, Pérez M, Avila J, Castellani RJ, Atwood CS, Aliev G, Sayre LM, Takeda A, Smith MA (2002) Is oxidative damage the fundamental pathogenic mechanism of Alzheimer's and other neurodegenerative diseases? Free Radic Biol Med 33:1475-1479.

15. Migliore L, Fontana I, Colognato R, Coppede F, Siciliano G, Murri L (2005) Searching for the role and the most suitable biomarkers of oxidative stress in Alzheimer's disease and in other neurodegenerative diseases. Neurobiol Aging 26:587-595.

16. Ashrafi MR, Shams S, Nouri M, Mohseni M, Shabanian R, Yekaninejad MS, Chegini N, Khodadad A, Safaralizadeh R (2007) A probable causative factor for an old problem: selenium and glutathione peroxidase appear to play important roles in epilepsy pathogenesis. Epilepsia 48:1750-1755.

17. Weijl NI, Hopman GD, Wipkink-Bakker A, Lentjes EG, Berger HM, Cleton FJ, Osanto S (1998) Cisplatin combination chemotherapy induces a fall in plasma antioxidants of cancer patients. Ann Oncol 9:1331-1337.

18. Smoorenburg GF, De Groot JC, Hamers FP, Klis SF (1999) Protection and spontaneous recovery from cisplatin-induced hearing loss. Ann NY Acad Sci 884:192-210.

19. Pocernich CB,Cardin AL, Racine CL, Lauderback CM, Butterfield DA (2001) Glutathione elevation and its protective role in acrolein-induced protein damage in synaptosomal membranes: relevance to brain lipid peroxidation in neurodegenerative disease. Neurochem Int 39:141-149.

20. Ayyıldız M, Coşkun Ş, Yıldırım M, Ağar E (2007) The effects of ascorbic acid on penicillin-induced epileptiform activity in rats. Epilepsia 48:1388-1395.

21. Kozan R, Ayyıldız M, Yıldırım M, Ağar E (2009) The effect of alpha-tocopherol in the acute ethanol intake and its withdrawal on penicillin-induced epilepsy. Acta Neurobiol Exp (Wars) 96:177-188.

22. Yıldırım M, Ayyıldız M, Ağar E (2010) Endothelial nitric oxide synthase activity involves in the protective effect of ascorbic acid against penicillin-induced epileptiform activity. Seizure 19:102-108. 
23. Hwang SL, Shih PH, Yen GC (2012) Neuroprotective effects of citrus flavonoids. J Agric Food Chem 60:877-885.

24. Rybak LP, Husain K, Morris C, Whitworth C, Somani S (2000) Effect of protective agents against cisplatin ototoxicity. Am J Otol 21:513-520.

25. Maclennan K, Darlington C, Smith P (2002) The CNS effects of Ginkgo biloba extracts and ginkgolide B. Prog Neurobiol 67:235- 257.

26. Clostre F (1986) From the body to the cell membrane: the different levels of pharmacological action of Ginkgo biloba extract,.., Presse Med 15:1529-1538.

27. Pincemail J, Dupuis M, Nasr C, Hans P, Haag-Berrurier M, Anton R, Deby C (1989) Superoxide anion scavenging effect and superoxide dismutase activity of Ginkgo biloba extract. Experientia 45:708-712.

28. Maitra I, Marcocci L, Droy-Lefaix MT, Packer L (1995) Peroxyl radical scavenging activity of Ginkgo biloba extract EGb 761. Biochem Pharmacol 49:649-655

29. Rong YQ, Geng ZH, Lau BHS (1996) Ginkgo biloba attenuates oxidative stress in macrophages and endothelial cells. Free Radic Biol Med 20:121-127.

30. Yoshikawa I, Naito Y, Kondo M (1999) Ginkgo biloba leaf extract: review of biological actions and clinical applications. Antioxid Redox Signal 1:469-480.

31. Bridi R, Crossetti FP, Steffen VM, Henriques AT (2001) The antioxidant activity of standardized extract of Ginkgo biloba (EGb 761) in rats. Phytother Res 15:449-451.

32. DeGregorio M, Wilbur B, King O, Wallenberg J, Prewitt S, Phillips J, Wilbur J. Peak cerebrospinal fluid platinum levels in a patient with ependymoma: evaluation of two different methods of cisplatin administration. Cancer Treat Rep. 1986;70(12):1437-8.

33. Steeghs, N, de Jongh, FE, Smitt PAE, Bent MJ. van den. Cisplatin-induced encephalopathy and seizures. Anti-Cancer Drugs. 2003; 14(6): 443-6

34. Watanabe KI, Hess A, Bloch W, Michel O (2000) Nitric oxide synthase inhibitor suppresses the ototoxic side effect of cisplatin in guinea pigs. Anticancer Drugs 11:401-406.

35. Yılmaz HR, Sögüt S, Özyurt H, Ozugurlu F, Şahin Ş, Işık B, Uz E, Özyurt H (2005) The activities of liver adenosine deaminase, xanthine oxidase, catalase, superoxide dismutase enzymes and the levels of malondialdehyde and nitric oxide after cisplatin toxicity in rats: protective effect of caffeic acid phenethyl ester. Toxicol Ind Health 21:67-73.

36. Güleç M, Iraz M, Yılmaz HR, Özyurt H, Temel I (2006) The effects of ginkgo biloba extract on tissue adenosine deaminase, xanthine oxidase, myeloperoxidase, malondialdehyde, and nitric oxide in cisplatin-induced nephrotoxicity. Toxicol Ind Health 22:125-130.

37. Kobuchi H, Droy-Lefaix MT, Christen Y, Packer L (1997) Ginkgo biloba extract (EGb 761): inhibitory effect on nitric oxide production in the macrophage cell line RAW 264.7. Biochemistry and Pharmacology 53:897-903.

38. Güleç M, Yılmaz R, Iraz M, Ağlamış S, Sögüt S (2004) The effects of ginkgo biloba extract on plasma glutathion peroxidase, superoxide dismutase, adenosine deaminase and nitric oxide levels in cisplatin-induced nephrotoxicity. Türkiye Klinikleri J Med Sci 24:585-591.

39. Nazıroğlu M, Karaoğlu A, Aksoy AO (2004) Selenium and high dose vitamin $\mathrm{E}$ administration protects cisplatin-induced oxidative damage to renal, liver and lens tissues in rats. Toxicology 195:221-230.

40. Saleh S, El-Demerdash E (2005) Protective effects of $\mathrm{L}$-arginine against cisplatin-induced renal oxidative stress and toxicity: role of nitric oxide Basic Clin Pharmacol Toxicol 97:91-97.

41. Pierre S, Jamme I, Droy-Lefaix MT, Nouvelot A, Maixent JM (1999) Ginkgo biloba extract (EGb-761) protects $\mathrm{Na}, \mathrm{K}$-ATPase activity during cerebral ischemia in mice. NeuroReport 10:47-51.

42. Oyama Y, Chikahisa L, Ueha T, Kanemaru K, Noda K (1996) Ginkgo biloba extract protects brain neurons against oxidative stress induced by hydrogen peroxide. Brain Res 712:349-352.

43. Ahlemeyer B, Mowes A, Krieglstein J (1999) Inhibition of serum deprivation- and staurosporine-induced neuronal apoptosis by Ginkgo biloba extract and some of its constituents. Eur J Pharmacol 367:423-430.

44. Huang X, Whitworth CA, Rybak LP (2007) Ginkgo biloba extract (EGb 761) protects against cisplatin-induced ototoxicity in rats. Otol Neurotol 28:828-833.

45. Xu O, Lu H, Li PQ, Zhang X, Lu Z (2004) Effect of combination of Ginkgo leaf extract and deferoxamine in preventing and treating ototoxicity of cisplatin Zhongguo Zhong Xi Yi Jie He Za Zhi 24:915-918. 